\title{
Cuckoo Search Based DTC of PMSM
}

\author{
A. Yassin', M. Badr' ${ }^{2}$, S. Wahsh ${ }^{3}$ \\ ${ }^{1,3}$ Departement of Power Electronics and Energy Conversion, Electronics Research Institute, Giza, Egypt \\ ${ }^{2}$ Departement of Electrical Engineering, Ain Shams University, Faculty of Engineering, Cairo, Egypt
}

\begin{tabular}{l}
\hline \hline Article Info \\
\hline Article history: \\
Received Dec 6, 2017 \\
Revised Apr 8, 2018 \\
Accepted Aug 6, 2018 \\
\hline
\end{tabular}

Keyword:

Cuckoo search algorithm

DTC

Optimization techniques

PMSM

Speed control

\begin{abstract}
Hysteresis controllers (HC) are used to limit the torque and flux in the control band in conventional configuration of direct torque control (DTC) while in the space vector pulse width modulated (SVPWM) DTC, the HC are switched to PI or PID controllers. This paper presents a modern approach for the speed control applied on a DTC of a permanent magnet synchronous motor (PMSM) using the Cuckoo Search Optimization (CSO) algorithm in order to optimize the PI speed controller parameters of the outer loop and PID flux and torque controllers of the inner loop. The system is tested at no load and with a step change in load. The performance of the controllers is presented and the results of simulation indicate a very rapid dynamic response and the system achieves the steady state (SS.) in a very short time. Also it shows that both the SS and dynamic performances are improved by applying of the CSO algorithm. The proposed DTC simulation model of the PMSM is presented using MATLAB/SIMULINK and capable of simulating both the steady-state and dynamic response. The CSO results are compared with another control strategy that incorporates fuzzy logic controller (FLC) with DTC.
\end{abstract}

Copyright () 2018 Institute of Advanced Engineering and Science. All rights reserved.

\section{Corresponding Author:}

A. Yassin,

Departement of Power Electronics and Energy Conversion,

Electronics Research Institute,

33 El-Tahrir st., Dokki, Giza, Egypt.

Email: amir@eri.sci.eg

\section{INTRODUCTION}

Due to attractive characteristics of PMSM, it has been universally used as a variable speed drive. Some of these features are its high efficiency, light weight, small volume and inertia hence high torque to inertia ratio, ease of control, maintenance free and high SS torque density [1]. Any high performance drive application generally requires fast torque response. AC drives have advantages of compactness, robustness, low maintenance, and economy. Due to growth in power electronic devices, great improvements in $\mathrm{AC}$ drives can be achieved. Variable frequency control strategies of AC machines include scalar control (SC) and field oriented or Vector Control (VC). SC uses magnitude and frequency control but VC uses orientation besides the magnitude. Variants include the DTC that also exploits orientation but aims to control the current and hence the torque via switching the voltage more directly [2].

In 1980, DTC was suggested for induction machines while it is applied on PMSM In late 1990's [3]. DTC principle has been widely used for motors drives with fast dynamics. Despite its simplicity, DTC strategies are capable of producing fast flux and torque control. The main advantages of DTC are absenc of co-ordinate transformation, no speed or position encoder is required and less dependence on the motor parameters. The main weakness of DTC is high torque ripples [4], [5]. The key element of a DTC drive is the estimation of stator flux linkage. DTC considered an accepted vector control way and one of the common control approaches for PMSM drives. With the purpose of taking full advantage of DTC, the control principle has to be considered [6]. 
Once using HC, large flux linkage and torque ripples are generated while in the SVPWM DTC the controllers are mainly exchanged with PI or PID controllers. In this paper, DTC scheme incorporating SVPWM inverter, for a PMSM speed control has been presented, that characterized by fast dynamic response with lower ripples in the torque and speed, lower dependency on the motor parameters and current controllers' elimination [7]. Now it is recognized that the high-performance control strategy for PMSM is the DTC and it can be implemented in the industrial products successfully. [8]

In recent years, researchers have acquired significant development on various control theories and methods. One of these control technologies are intelligent control methods like fuzzy logic (FL), neural network, genetic algorithm, particle swarm (PS), ant-colony, gray wolf, simulated annealing, expert system etc. Simplicity and no need for mathematical model are the main features of these controllers that are suitable for nonlinearities and uncertainties of electrical machines [9].

Recently, researches are made in DTC of PMSM based on FL-type-1, FL-type-2 and artificial neural network and in controlling PMSM using the DTC strategy with PS optimization technique or by using combination of control strategies and optimization techniques like tuning PI-controller using swarm algorithm or intelligent FLC using PS optimization [10-16]. Nowadays, PS algorithms have become famous due to its simplicity. CSO is considered to be one of the latest swarm intelligence algorithms [17], which is based on simulating the searching behavior of a certain family of birds which is Cuckoo birds [18-20], which have an destructive life style which appears in the reproduction phase of their life, where these birds put their eggs on common nests with other birds [19], [21].

CSO idealized such breeding behavior, and can be applied in several optimization problems. It seems that it can outperform other metaheuristic algorithms in applications [21]. The CSO starts with an initial generation of particles. These first particles or cuckoos have some eggs to lay in several host birds' nests. Some of these eggs which are more like to the host bird's eggs have the chance to pick up and become an old bird. The rest eggs are identified by host birds and are destroyed. The big eggs show the suitability of the nests in that environment. The more eggs survive in an environment, the more profit is achieved in that territory. Therefore the location in which large eggs how survive would be the term that CSO is going to optimize [22].

In CSO, each egg inside nest acts as a solution but a cuckoo egg constitutes a new solution. The target is to utilize new and potentially superior solutions to replace less superior solution in the nests. Each nest contains one egg in simplest form and the algorithm can be stretched to more complex cases where each nest contains multiple eggs that represent set of solutions. The features of the CSO are its capability to concurrently refine a local search, as searching globally solution in search space and it is speedy, requiring a low time to discover the optimum result in search space [21]. In this paper, CSO is used to optimize control parameters PID controllers of DTC of PMSM and a comparison between this configuration and incorporating FLC to the DTC scheme will presented.

\section{RESEARCH METHOD}

The DTC basic principle is to control electromagnetic torque $\left(\mathrm{T}_{\mathrm{e}}\right)$ and stator flux $\left(\psi_{\mathrm{s}}\right)$ directly by selecting an optimum voltage vector according to the difference between reference and actual values of torque and flux. The basic DTC scheme that incorporates hysteresis comparators is shown in Figure 1.

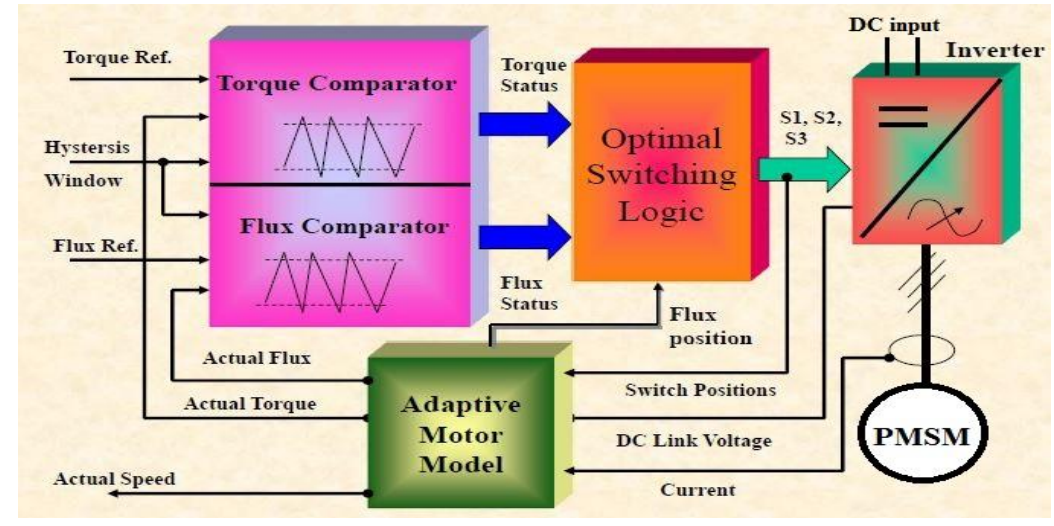

Figure 1. The basic DTC Technique

This paper presents the DTC using SVPWM. SVPWM technique enables operation at a constant switching frequency. Based on the instantaneous values of current and voltage it is possible to calculate the 
required voltage to force $T_{e}$ and $\psi_{s}$ to the needed values within a fixed time period. This calculated voltage is then synthesised using SVPWM. For estimating instantaneous flux and the output torque, applied voltage values and motor currents can be used.

To test the algorithms the system was simulated using the Simulink-Power-System Blockset that permits a complete representation of the power section (inverter and PMSM) and control system. The control algorithms were constructed, and then the whole drive system is simulated and tested to verify the concept and analysis of DTC. Figure 2 represents the proposed PMSM drive block diagram with DTC using SVPWM.

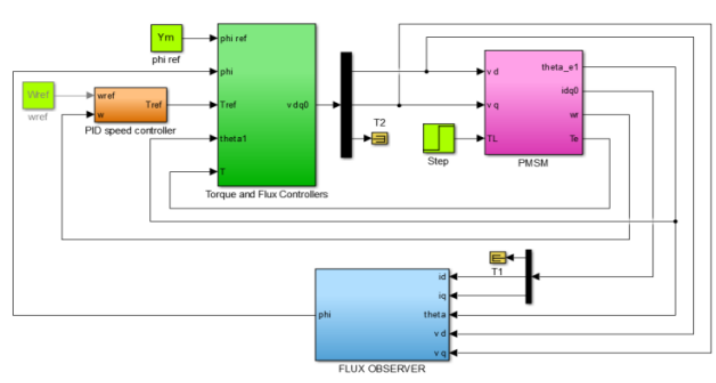

Figure 2(a). Overall Proposed System

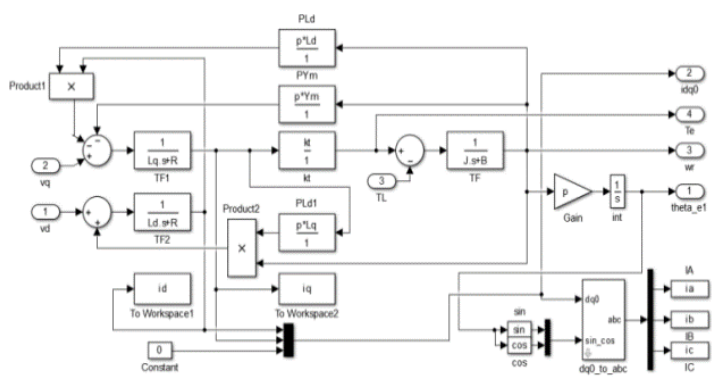

Figure 2(c). PMSM Block

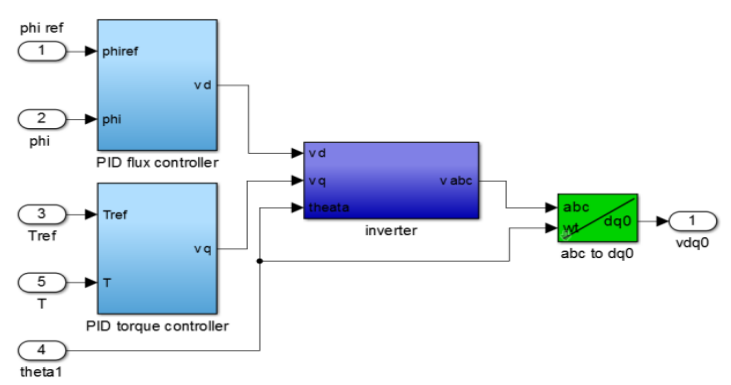

Figure 2(b). Torque and Flux Controllers Block

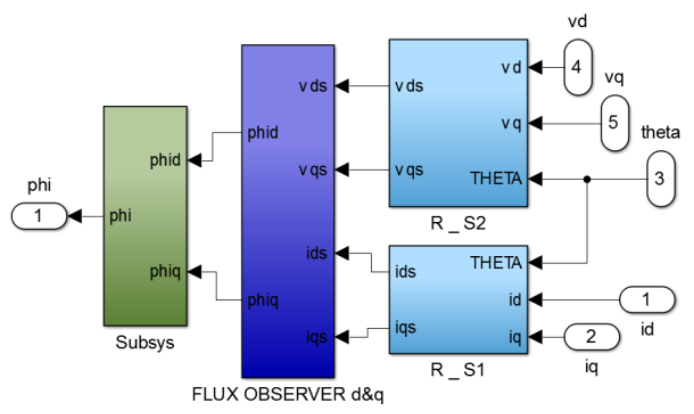

Figure 2(d). Flux Observer Block

Figure 2. The proposed DTC scheme of the PMSM with SVPWM

The system consists of inner torque loop, inner stator flux loop and finally an outer speed loop. Whenever a speed command $\left(\omega_{\text {ref }}\right)$ is given, the system automatically compares it with actual speed $\left(\omega_{\mathrm{r}}\right)$ since the error of speed directly reflects torque, the output of speed PI controller is used as a reference torque $\left(\mathrm{T}_{\text {ref }}\right)$ to make the necessary torque adjustment. Once the proper adjustment is done, $\omega_{\mathrm{r}}$ should follow the given reference $\omega_{\text {ref. }}$ Simultaneously, the DTC system samples stator current and DC link voltage, which are used to estimate $\psi_{\mathrm{s}}$ and $\mathrm{T}_{\mathrm{e}}$. These values are compared with stator flux reference value $\left(\psi_{\text {ref }}\right)$ and $\mathrm{T}_{\text {ref }}$ respectively. Based on these results, an optimal voltage signals are generated and used to calculate the timing of SVPWM signals, which is sent out to the switches gating to control the motor drive [23], [24].

\section{SIMULATION RESULTS AND DISCUSSION}

A standard approach for speed control in drives is the use of a PI controller. Recent developments in artificial intelligence based control have brought in to focus a possibility of optimizing all the control parameters. In this research work all the parameters of the PI speed controller of the outer loop and PID flux and torque controllers of the inner loop are optimized using CSO algorithm.

The system is tested at reference speeds equals $1000 \mathrm{rpm}$ and $2000 \mathrm{rpm}$ at no load and when loaded with $1 / 4$ of full load $\left(0.55\right.$ N.M) and half load $\left(1.1\right.$ N.M) with a step change in load. The value of $\psi_{\text {ref }}$ is 0.29 $\mathrm{Wb}$ and switching time (Ts) equals $0.0002 \mathrm{sec}$ and the motor data used is reported in appendix (A).

\subsection{At No Load}


Figure 3 shows the simulation result at no load at $1000 \mathrm{rpm}$ reference speed with PI speed controller and PID flux and torque controllers optimized by CSO. The system reaches its SS. in time less than 0.0142 sec with $0.934 \%$ overshoot and $-0.0146 \%$ SS. error.

Figure 4 indicates the simulation result at no load at $2000 \mathrm{rpm}$ reference speed with PI speed controller and PID flux and torque controllers optimized by CSO. The system reach its SS. in time less than $0.6 \mathrm{sec}$ with $8.9 \%$ overshoot and $0.0014 \% \mathrm{SS}$. error, the flux response is maintained to its predetermined value with $1.7 \% \mathrm{SS}$. error.

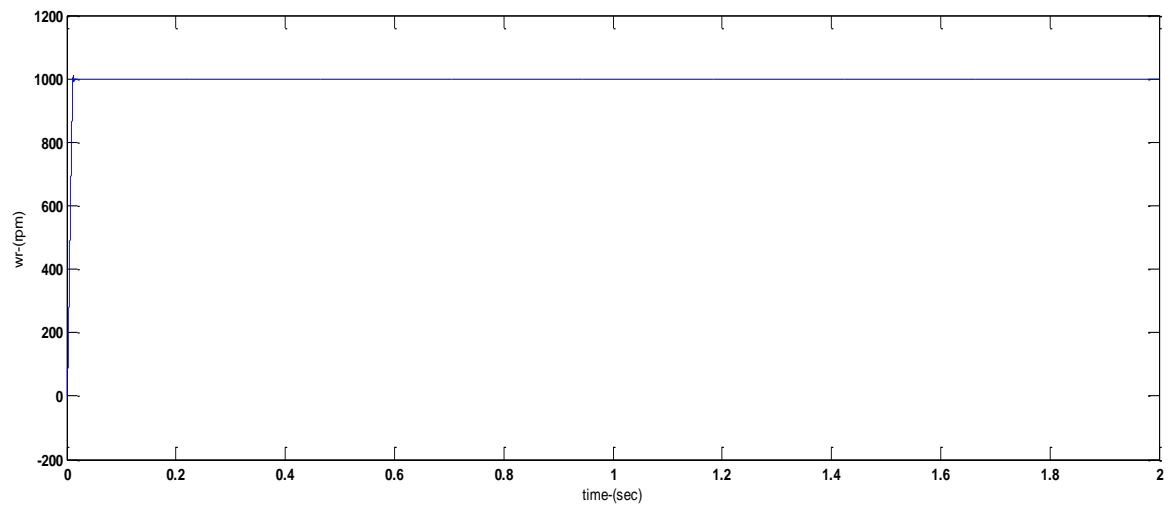

Figure 3(a). Motor Speed

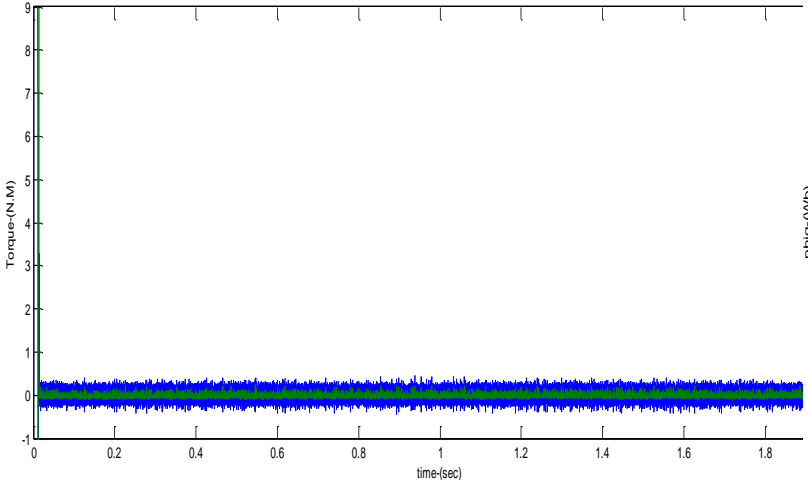

Figure 3(b). Te \& Tref

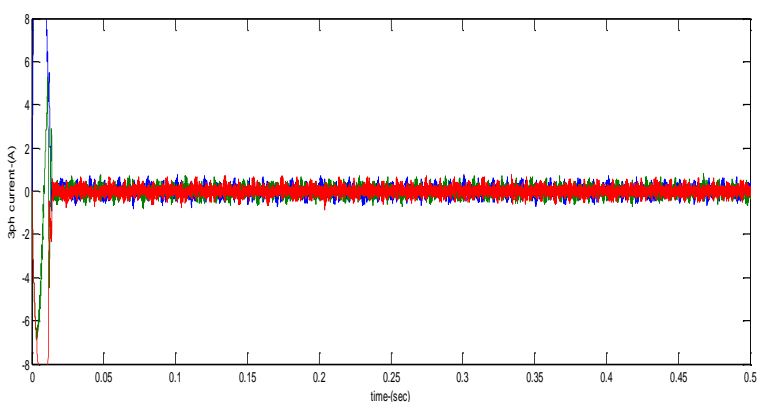

Figure 3(d). Three Phase SS. Current

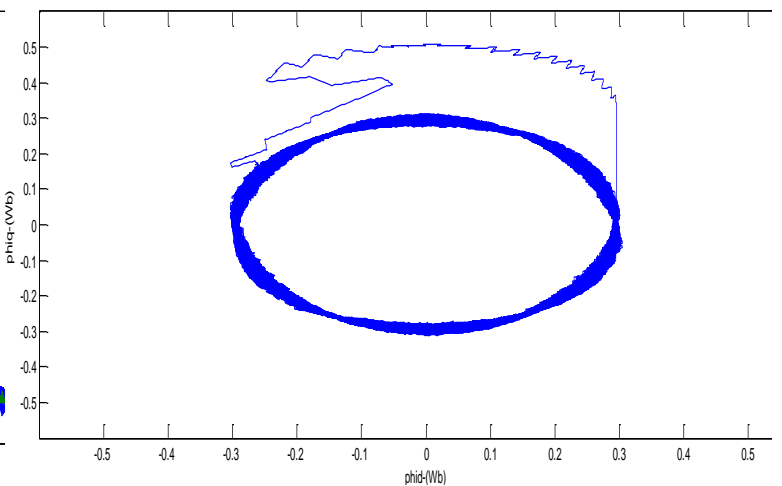

Figure 3(c) Flux Locus

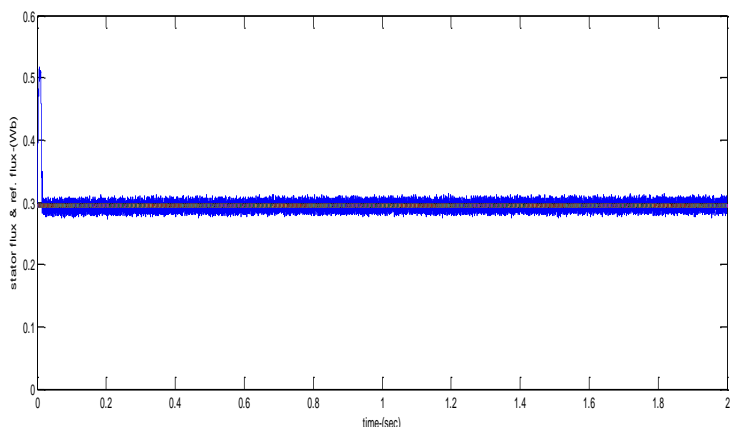

Figure 3(e). $\Psi_{\mathrm{S}}$

Figure 3. Simulation Results at No Load and Reference Speed of $1000 \mathrm{rpm}$ Under DTC with PI Speed Controller and PID Flux and Torque Controllers Optimized by CSO 


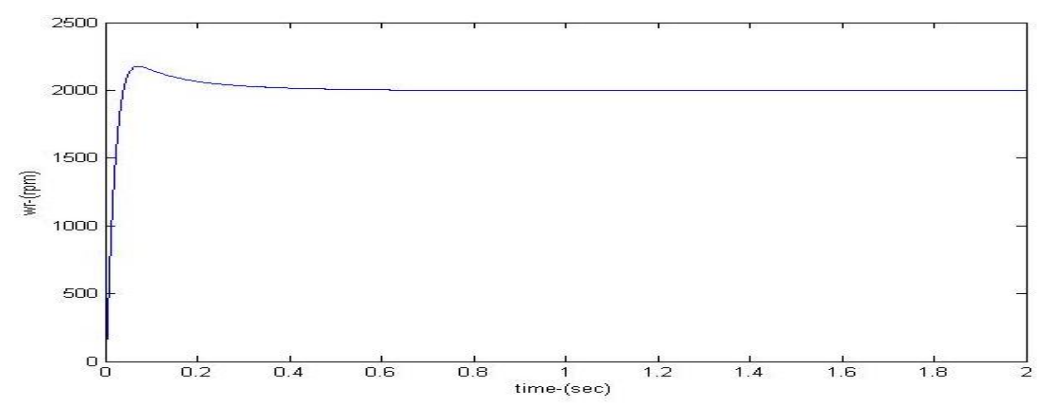

Figure 4(a). Motor Speed

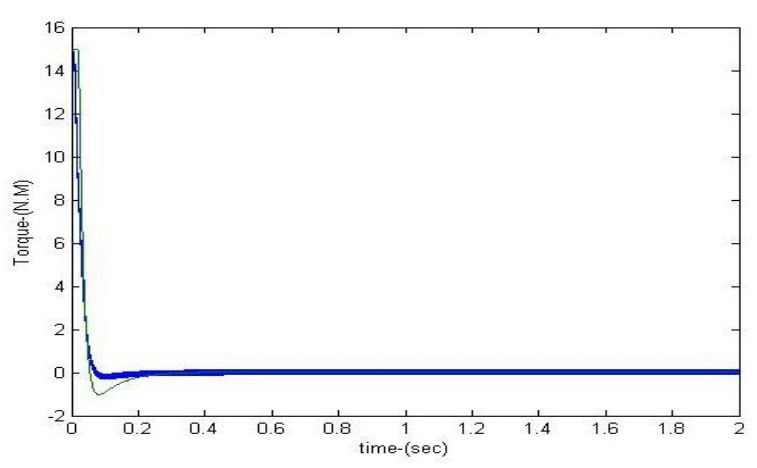

Figure 4(b). Te \& Tref

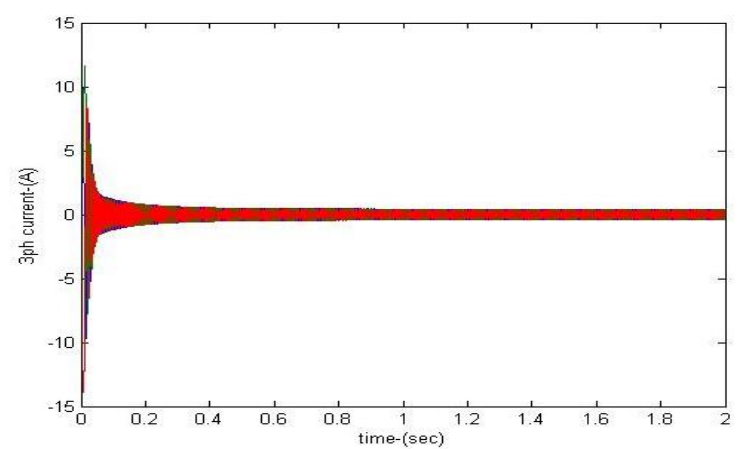

Figure 4(d). Three Phase SS. Current

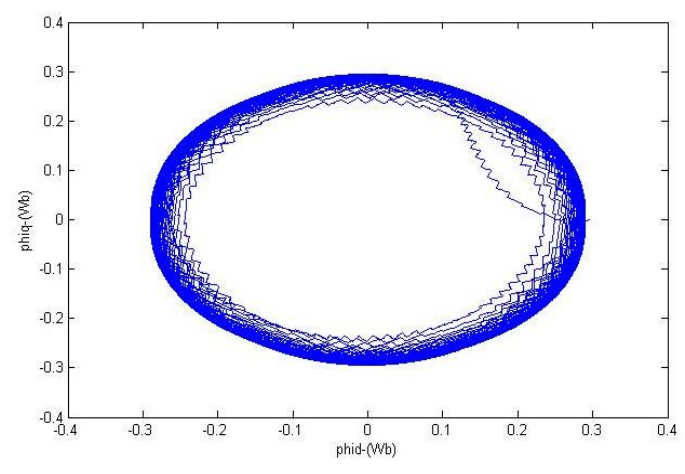

Figure 4(c). Flux Locus

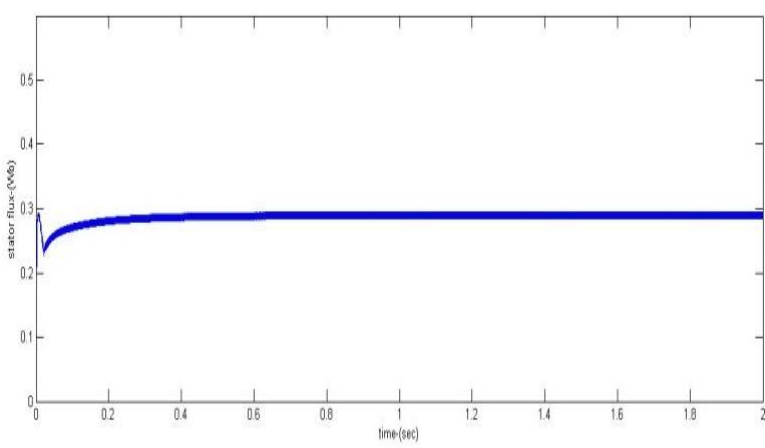

Figure 4(e). $\Psi s$

Figure 4. Simulation Results at No Load and Reference Speed of $2000 \mathrm{rpm}$ Under DTC with PI Speed Controller and PID Flux and Torque Controllers Optimized by CSO.

\subsection{When Loaded}

The system is loaded with 0.55 N.M and 1.1 N.M with a step change in load at $\mathrm{t}=1.0 \mathrm{sec}$. Figure (5) shows the simulation result at this loading case at $1000 \mathrm{rpm}$ reference speed with PI speed controller and PID flux and torque controllers optimized by CSO. The system reach its SS. in time less than $0.0143 \mathrm{sec}$ with rise time equals $0.0118 \mathrm{sec}, 0.7006 \%$ overshoot and $-0.0255 \%$ SS. error. 


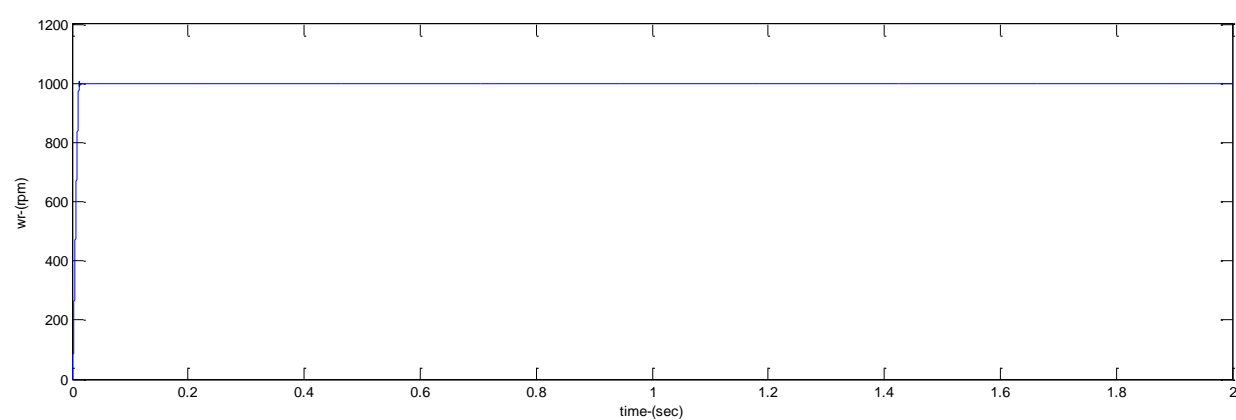

Figure 5(a). Motor Speed

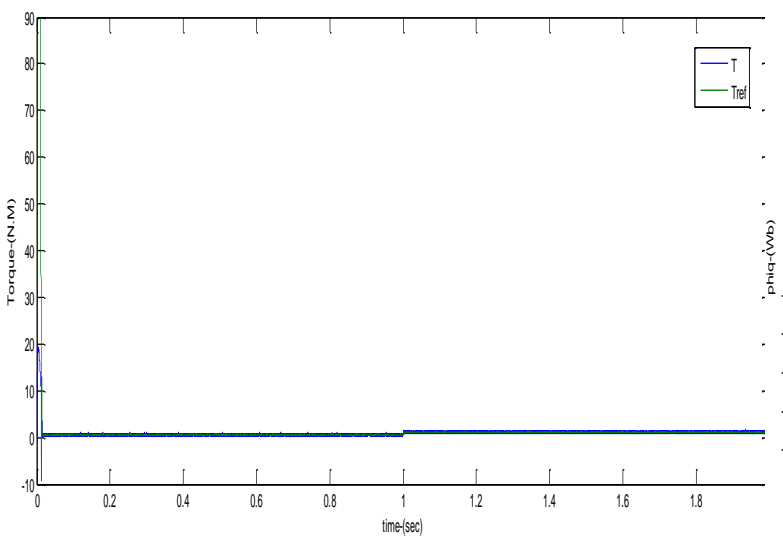

Figure 5(b). Te \& Tref

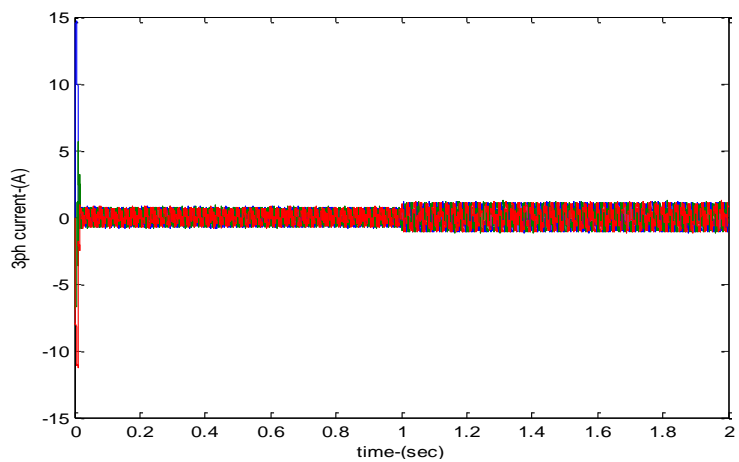

Figure 5(d). Three Phase SS. Current

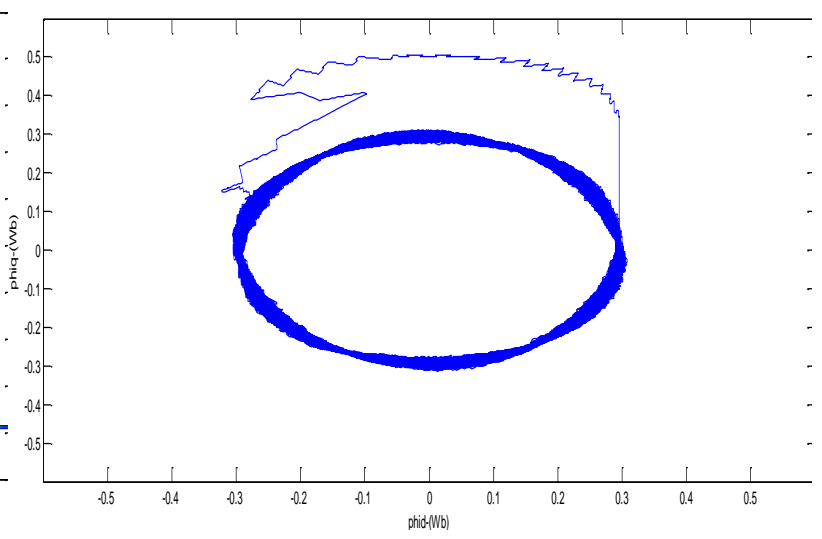

Figure 5(c). Flux Locus

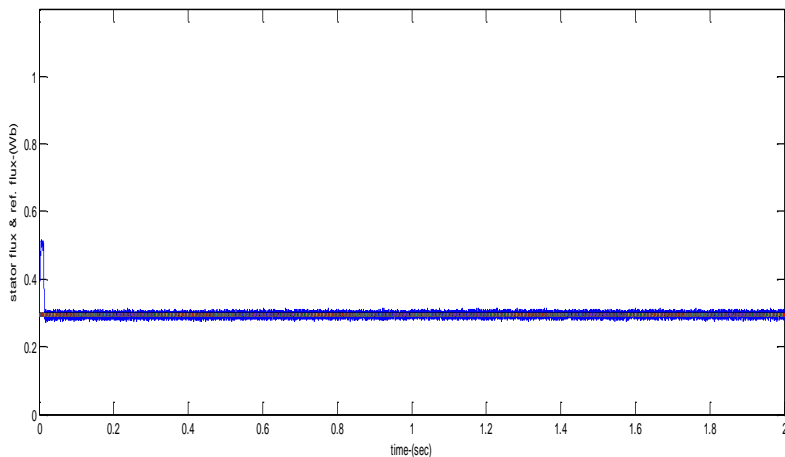

Figure 5(e). $\Psi$ s

Figure 5. Simulation Result at Reference Speed of $1000 \mathrm{rpm}$ and Load Step Change from 0.55 NM to 1.1 NM at $\mathrm{t}=1.0 \mathrm{Sec}$ Under DTC with PI Speed Controller and PID Flux and Torque Controllers Optimized by CSO

Figure 6 shows the system simulation result at this loading case at $2000 \mathrm{rpm}$ reference speed with PI speed controller and PID flux and torque controllers optimized by CSO. The system reach its SS. in time less than $0.51 \mathrm{sec}$ with rise time equals $0.0393 \mathrm{sec}, 8.9 \%$ overshoot and $-0.002 \% \mathrm{SS}$. error. 


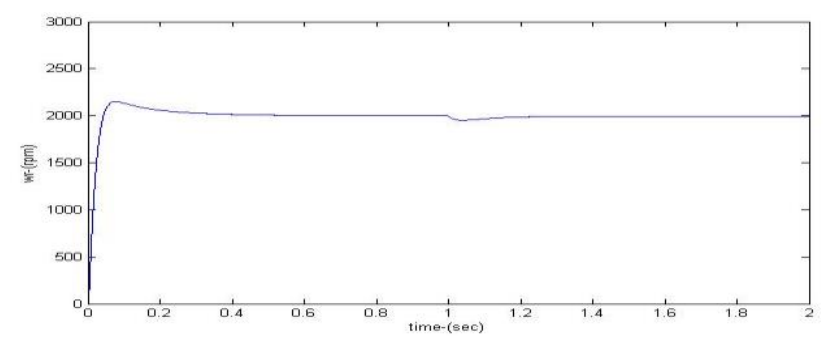

Figure 6(a). Motor Speed

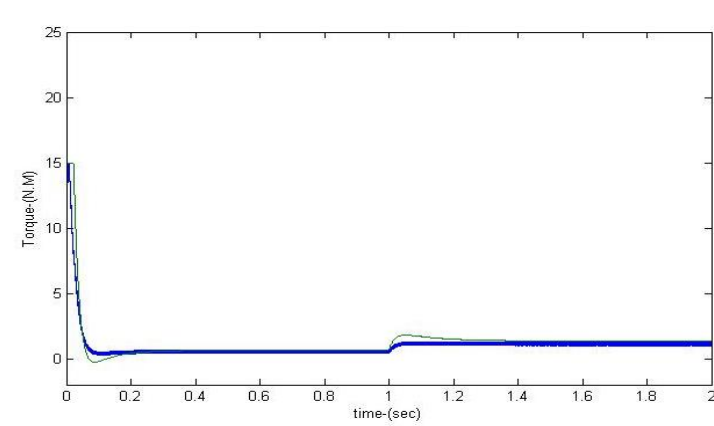

Figure 6(b). Te \& Tref

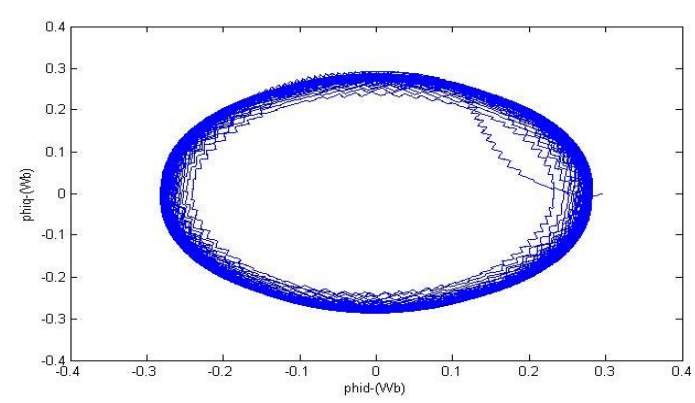

Figure 6(d). Flux Locus

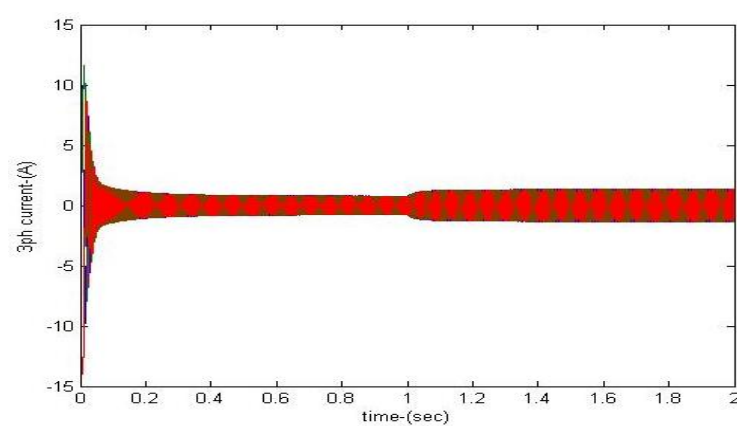

Figure 6(c). Three Phase SS. Current

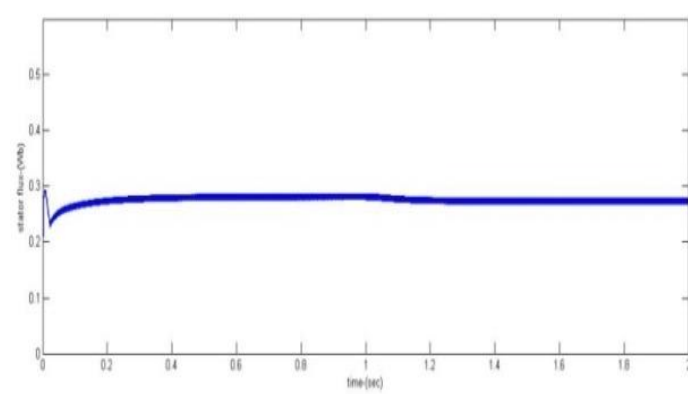

Figure 6(e). $\Psi \mathrm{s}$

Figure 6. Simulation Result at Reference Speed of $2000 \mathrm{rpm}$ and Load Step Change from $0.55 \mathrm{NM}$ to 1.1 $\mathrm{NM}$ at $\mathrm{t}=1.0 \mathrm{Sec}$ Under DTC with PI Speed Controller and PID Flux and Torque Controllers Optimized by CSO

Figures 3, 4, 5 and 6 show that the DTC using SVPWM with optimizing PID controllers by CSO can produce very rapid changes in torque output under transient conditions while maintaining low current distortion in steady-state operation. Also a rapid torque dynamic response can be noted and the system achieves the steady status in less than $0.51 \mathrm{sec}$.

\section{COMPARISON WITH FUZZY 1\&2}

The research work [25] introduces the same motor to test the controller capability at various conditions under DTC using SVPWM with both FL-type-1, FL-type-2 controllers replacing the PI speed controller with a FLC and keeping both PID flux and torque controllers. Table 1 presents the simulation results of DTC of PMSM using SVPWM with both FL-type-1, FL-type-2 controllers and with optimizing PID controllers by CSO at reference speed equals $2000 \mathrm{rpm}$ when the motor loaded with 0.55 N.M and 1.1 N.M with a step change in load at $\mathrm{t}=1.0 \mathrm{sec}$. 
Table 1. Comparison at 2000 rpm Reference Speed when Loaded with 0.55 N.M and 1.1 N.M with a Step Change in Load at $\mathrm{t}=1.0 \mathrm{sec}$

\begin{tabular}{|c|c|c|c|c|}
\hline \multicolumn{2}{|c|}{ PMSM response } & Fuzzy-1 & Fuzzy-2 & $\mathrm{CSO}$ \\
\hline \multirow{5}{*}{ Speed response } & Ripples & $0.005 \%$ & $0.0005 \%$ & $0.002 \%$ \\
\hline & Rise time & $60 \mathrm{~ms}$ & $47 \mathrm{~ms}$ & $39.3 \mathrm{~ms}$ \\
\hline & S.S time & $420 \mathrm{~ms}$ & $380 \mathrm{~ms}$ & $510 \mathrm{~ms}$ \\
\hline & Overshoot & $0 \%$ & $0.2 \%$ & $8.9 \%$ \\
\hline & S.S. error & $0.75 \%$ & $-0.275 \%$ & $-0.002 \%$ \\
\hline
\end{tabular}

Comparing all the results it is obvious that CSO optimized controllers introduces improved performance in starting and SS. where it reduces the SS. error of the system and reduces the rise time also it has less ripples but the FL-type-1 and FL-type-2 controllers introduce less overshot. These comparison results may open a way to deep use of optimization techniques with electrical motor controllers to get better performance.

\section{CONCLUSION}

In this research article, an optimization based on CSO algorithm is introduced to enhance both the SS. and dynamic performances of a DTC speed controller of a PMSM. Variables of the PI speed controller of the outer loop and two PID controllers for the flux and torque of the inner loop are chosen as design variables whose values are tuned in CSO procedure for the PMSM Control. The drive system components has been simulated using MATLAB SIMULINK and simulation is performed for several cases,

Simulation results indicate that this new control strategy provides a good dynamic response and improves the SS. performance. The use of CSO as an optimization algorithm enhances the control performance. The configuration of optimizing the PI and PID parameters of the controllers using CSO is compared with that uses FLCs with DTC. From the comparison, it may be concluded that the responses with the DTC are quicker and the DTC system has a much better SS. performance while retaining the good dynamic performance and the new proposed control strategy dominates the control output to significantly reduce SS. error of the system. The experimental set up is going on and the practical test will be reported later.

\section{REFERENCES}

[1] Gupta, N. P., and Gupta, P., Performance analysis of direct torque control of PMSM drive using SVPWM-inverter, IEEE 5th India International Conference on Power Electronics (IICPE), 08 Dec 2012, Delhi, India, pp 1-6.

[2] Finch, J. W., and Giaouris, D., Controlled AC electrical drives, IEEE Transactions on Industrial Electronics, 55(2), 2008, pp 481-491.

[3] Tang, L., Zhong, L., Rahman, M. F., and Hu, Y.,A novel direct torque control for interior permanent-magnet synchronous machine drive with low ripple in torque and flux-a speed-sensorless approach, IEEE Transactions on Industry Applications, 39(6), 2003, pp1748-1756.

[4] Malla, S. G., and Malla, J. M. R., Direct torque control of induction motor with fuzzy controller: A review, International Journal of Emerging Trends in Electrical and Electronics (IJETEE)10(3),2014, pp1-16.

[5] Li, Y., Jian, M., Qiang, Y., \& Jiangyu, L., A novel direct torque control permanent magnet synchronous motor drive used in electrical vehicle., International Journal of Power Electronics and Drive Systems, 2011, 1(2), 129.

[6] Chikh, K., Saad, A., Khafallah, M., Yousfi, D., Tahiri, F. Z., \& Hasoun, M., A Constant Switching Frequency DTC for PMSM Using Low Switching Losses SVM-An Experimental Result., International Journal of Power Electronics and Drive Systems, 2017, 8(2), 558.

[7] Wahsh, S., Abdelaziz, M., and Ahmed, Y. Fuzzy logic control of direct torque control PMSM drives using space vector technique. Proceeding of Fuzzy Theory and Intelligent Informatics conference (SCIS and ISIS),Tokyo, Japan, 2006, pp 766-771.

[8] Merzoug, M. S., and Naceri, F., Comparison of field-oriented control and direct torque control for permanent magnet synchronous motor, Proceedings of world academy of science, engineering and technology , Nov., 2008, Vol. 35, pp. 299-304.

[9] Uddin, M. N., and Wen, H., Development of a self-tuned neuro-fuzzy controller for induction motor drives. IEEE Transactions on industry applications, 43(4), 2007,pp 1108-1116.

[10] Elwer, A. S., and Wahsh, S. A., Improved performance of permanent magnet synchronous motor by using particle swarm optimization techniques, Chinese Control Conference(CCC 2007), Zhangjiajie, China, 26 - 31 Jul 2007, pp. 326- 330.

[11] Wahsh, S., Ahmed, Y., and El Aziz, M. A., Intelligent control of PMSM drives using type-2 fuzzy, International Conference on Renewable Energy Research and Applications (ICRERA), Nagasaki, Japan, 11-14 Nov, 2012, pp. 1-6. 
[12] Elwer, A. S., Wahsh, S. A., Khalil, M. O., and Nur-Eldeen, A. M., Intelligent fuzzy controller using particle swarm optimization for control of permanent magnet synchronous motor for electric vehicle, 29th Annual Conference of the Industrial Electronics, (IECON 2003), IEEE, Roanoke, VA, USA, 2-6 Nov. 2003, Vol.2 , pp 1762-1766.

[13] Elwer, A. S., Wahsh, S. A., Saleh, K., and Badr, M. A., Analysis of permanent magnet synchronous motor using artificial neural network for electric vehicles, International Conference on Information and Communication Technologies: from Theory to pplications"ICTTA04", 19-23 April 2004., Damascus, SYRIA, pp. 143- 144.

[14] Liu, J., Wu, P., Bai, H., and Huang, X., Application of fuzzy control in direct torque control of permanent magnet synchronous motor, Fifth World Congress on Intelligent Control and Automation (WCICA 2004), Hangzhou, China, 15-19 June 2004, Vol. 5, pp. 4573-4576.

[15] Sun, D., He, Y., and Zhu, J. G., Fuzzy logic direct torque control for permanent magnet synchronous motors,. Fifth World Congress on Intelligent Control and Automation(WCICA 2004) Hangzhou, China, 15-19 June 2004, Vol. 5, pp. 4401- 4405 .

[16] Sun, D., Zhu, J., and He, Y., Direct torque control of permanent magnet synchronous motor based on fuzzy logic., Australasian Universities Power Engineering Conference (AUPEC), Melbourne, Australia, 29th Sep - 2nd Oct., 2002

[17] Gandomi, A.H., Yang, X.-S., Alavi, A.H., Cuckoo search algorithm: A metaheuristic approach to solve structural optimization problems, Engineering with Computers, 2013, pp17-35.

[18] Zhou, Y., Zheng, H., Luo, Q., Wu, J., An improved cuckoo search algorithm for solving planar graph coloring problem, Applied Mathematics and Information Sciences, 2013,pp785-792.

[19] Algabalawy, M., Optimal multi-criteria design of hybrid power generation systems, PHD thesis, Ain Shams University, Egypt, 2017.

[20] Wahsh, S., Badr, M., Algabalawy, M., Yassin, A., Cuckoo search meta-heuristic algorithm: developments and applications, 5th International Conference on Advanced Control Circuits And Systems (ACCS'017), Alexandria, Egypt, 5 - 8 November 2017.

[21] Zayandehroodi, H., Nasrabadian, A., and Anoosheh, R., Cuckoo optimization algorithm based design for low-speed linear induction motor, Cumhuriyet Science Journal, 36(6), 2015,pp 29-38 .

[22] Rajabioun, R., Cuckoo Optimization Algorithm. Applied Soft Computing, 11,3, 2011,pp 5508-5518.

[23] Kazmierkowski, M. P., and Buja, G., Review of direct torque control methods for voltage source inverter-fed induction motors, 29th Annual Conference of the Industrial Electronics (IECON'03.) Roanoke, VA, USA, 2-6 Nov. 2003. Vol. 1, pp. 981-991.

[24] Habetler, T. G., Profumo, F., Pastorelli, M., and Tolbert, L. M., Direct torque control of induction machines using space vector modulation, IEEE Transactions on Industry Applications, 28(5), 1992, pp1045-1053.

[25] Ahmed, Y., Implementation of type-2 FLC in PMSM drives for plug-in hybrid electric vehicles using DSP. PHD thesis, Cairo University, Egypt, 2014.

\begin{tabular}{cc} 
APPENDIX \\
Appendix. PMSM Parameters \\
\hline Data & Value \\
\hline Rated speed in rpm (wrated) & 3000 \\
Rated torque in N.M (Trated) & 2.2 \\
No. of Pair Poles (p) & 3 \\
Winding resistance in ohm (R). & 11.0 \\
Winding inductance in mH. (Lw) & 25 \\
Rotor moment of inertia in kg.m ${ }^{2}(\mathrm{~J})$ & 1.6 \\
Maximum Flux in Wb (Ym) & 0.295 \\
Dc Link Voltage in V (Vdc) & 350.0 \\
\hline
\end{tabular}

\section{BIOGRAPHIES OF AUTHORS}

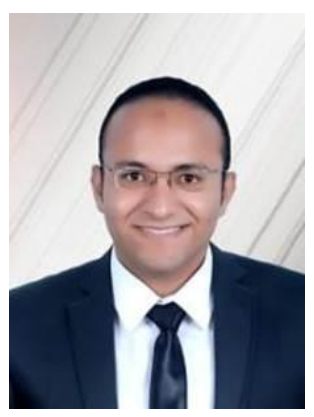

Eng. A. Yassin received his B.Sc. with excellent grade with honor degree in Electrical Engineering from Fayoum University, Egypt, in June 2010. In 2011 he joined the Electronics Research Institute (ERI) as a Researcher Assistant at Power Electronics and energy conversion department. A. Yassin obtained his M.Sc. from Fayoum University at 2014 and he became an Assistant Researcher in ERI. He was honored as "The Best Assistant Researcher" at ERI for years 2016 and 2017 respectively also he is awarded as the winner in "Engineering Innovation Competition 2015" at Egyptian Engineers Syndicate. His major interests are: Electrical Drives Control, Modeling and Simulation of Electrical Systems, Artificial Intelligence, Thermal Modelling and Electrical/Hybrid Vehicles Modeling, Simulation, and Control. 


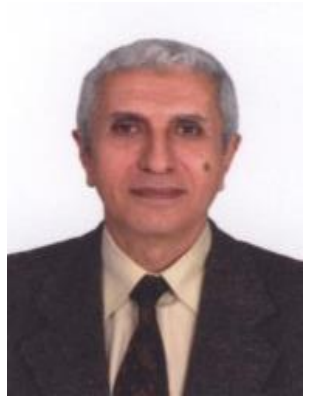

Prof. S. WAHSH received his B.Sc. degree in Electrical Engineering from Ain Shams University, Cairo, in June 1967. In 1973 he joined the National Research Center (NRC) as a researcher. He received his Ph.D. in Electric Drives from Budapest Technical University, Hungary in January 1980. Since 1980 he has been working as an assistant professor in the Electronics Research Institute (ERI). From 1984 till 1998 he was head of Power Electronics and Energy Conversion Dept., ERI. In 1990 he became a professor of Power Electronics in ERI. He has authored more than a hundred thirty articles in the field of modeling, analysis and control of DC, IM, SRM and PMSM. Furthermore, he has supervised several M Sc and PhD thesis. He has also managed several projects as principal investigator. Prof. Wahsh works part time in various Egyptian universities. He also is acting as member in evaluating committee of university staff. He was a visiting professor for various foreign universities. He has done a considerable amount of consulting engineering work in Industrial Electronics .His major field of interest includes Power Electronics, Electric Drives, Motion Control and Electrical/Hybrid Vehicles.

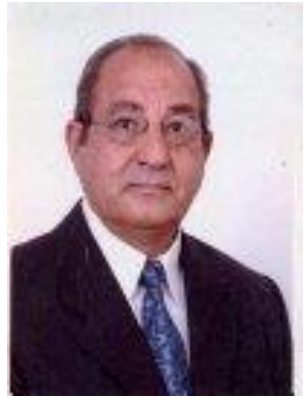

Prof. Mohamed A. L. Badr was born in Cairo, Egypt in 1944. He received the B. Eng. Degree (Honors) and M. Sc. in electrical engineering from Ain-Shams University in Cairo, Egypt in 1965 and 1969, respectively. He received Ph. D degree from the Polytechnic Institute of Leningrad in the former Soviet Union in 1974. Currently he is emeritus professor of electrical power and machines in Ain Shams University. Dr. M. A. L. Badr had been Professor of Electrical Machines in Ain Shams University since 1984. He had been the chairman of the Dept. of Electrical Power and Machines for 6 years. He headed the Electrical Engineering Dept. at the University of Qatar at Doha for five years. He was granted a post-doctor fellowship at the University of Calgary, Alberta, Canada between 1980 and 1982. Dr. Badr is a senior member IEEE since 1990. Dr. Badr has supervised a large number of Ph. D. and. M. Sc. research work in electrical machines and power systems, the areas in which he is interested. He is the author and co-author of many published refereed papers. 